\title{
Paper Machine Industrial Analysis on Moisture Control Using BF-PSO Algorithm and Real Time Implementation Setup through Embedded Controller
}

\begin{abstract}
M.Senthil Kumar ${ }^{\dagger}$ and K.Mahadevan*
Abstract - Proportional Integral Derivative (PID) controller tuning is an area of interest for researchers in many areas of science and engineering. This paper presents a new algorithm for PID controller tuning based on a combination of bacteria foraging and particle swarm optimization. BFO algorithm has recently emerged as a very powerful technique for real parameter optimization. To overcome delay in an optimization, combine the features of BFOA and PSO for tuning the PID controller. This new algorithm is proposed to combine both the algorithms to get better optimization values. The real time prototype model of paper machine is designed and controlled by using PIC microcontroller embedded with the programming in $\mathrm{C}$ language.
\end{abstract}

Keywords: Paper industry, PSO, PID, BFO, BF-PSO

\section{Introduction}

Paper finds its place in list of unavoidable things that is used in nook and corner of the world. Paper application is of wide range from domestic usage to industrial usage. The paper can be produced in the best quality by completely removing the water content from the pulp of paper and hence the paper machine is designed. Fig. 1 represents the block diagram of paper process and removal of moisture in various stages Paper machine contains three sections namely, the wire section, the press section, and drying section [1-8]. At the initial stage the chemical and mechanical pulp from pulp mills and chip refineries respectively are mixed with additives and chemicals. In the wire section, once the stock enters it contains less than $1 \%$ fibre, it is then carried to the long slice on the wire were the water is removed by gravitational force or by section below, then web is produced by adherence of cellulose fibre due to the hydrogen bond. In the press section, $20 \%$ of dry solid content exist, the water content is removed by pressing with rotating steel rolls and then by press felt. Nip (gap between two rolls) and felt (which depends on construction) decides the effectiveness of water removal process. Next the paper web encounters the drying section with a solid content of 50\% approximately. A large number of iron cylinders are present in drying section and are steam heated. Moist paper adhered around the cylinder and is dried by evaporation in latent heat of vaporisation in the steam. The drying rate depends on basis weight of dryer,

$\uparrow \quad$ Corresponding Author: Dept. of Electrical and Electronics Engineering, Syed Ammal Engineering College, Ramanathapuram-(623 502) Tamilnadu, India. (msenthilkumar040682@gmail.com)

* Dept. of Electrical and Electronics Engineering, PSNA College of Engineering and Technology, Dindigul -624 622, Tamil Nadu, India. Received: May 23, 2015; Accepted: September 14, 2015 speed and the moisture content. Reduction in energy consumption is done by increased efficiency of evaporation and by using minimum number of layer cylinders. Steam pressure is controlled by individual dryer groups in the dryer cylinders, which in turn adjusted to control moisture in paper web. It can also be controlled by desired heat flow to the paper $70 \%$ of steam usage is done in drying section. Finally the paper which is wound on a big roll has been removed from the paper machine. Finally moisture content reaches unto $5 \%$ to $10 \%$ which decides the paper quality. A technically advanced paper machine achieves 1000 tons of paper production per day, hence $0.1 \%$ reduction of moisture content will save 365 tons of raw material per year. Paper drying operation depends on i) Temperature and steam pressure ii) Temperature and humidity of air iii) Energy content of steam and iv) Heat and mass transfer co-efficient. Economic welfare of a welltuned moisture control system is achieved by operating it at maximum speed with control constraints to attain maximum production. Speed can be increased devoid of need of maximum steam pressure because of reduced variations in moisture, and grade change timing is also reduced. Dry lib is used for mathematical modelling of the drying section. During grade change moisture feedback loop is turned off and operation is carried out in open loop (feed forward). Due to model errors, i.e. the set point will be deviated in the moisture present in feed forward loop.

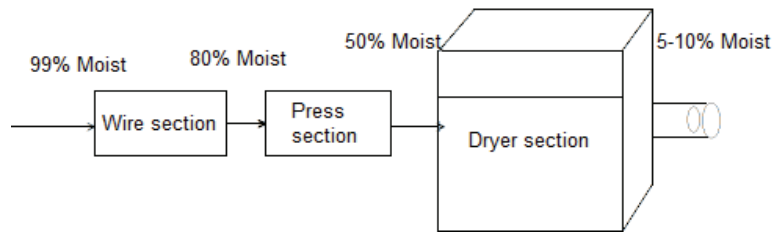

Fig. 1. Principle of paper production 
This emphasise the vital part of moisture control in grade change final stage and the economic profit lies in the shorter grade change time.

\subsection{Machine Direction (MD) moisture control}

The quality control system (QCS) is divided in two separate dimensions, the machine direction control (MD) and the cross direction control (CD). The conventional technique is to measure the $\mathrm{MD}$ and $\mathrm{CD}$ signals by scanning the sheet with a single sensor. The sensor is mounted in a scanner platform, where it moves back and forth in the cross direction. See Fig. 2. The primary mechanism today for the control of the moisture MD variations is the dryer steam pressure. The moist paper can be led around a single large steam heated cylinder, called Yankee cylinder (mainly used for the drying of tissue) or a large number of steam heated cast iron cylinders in series (commonly called cans), called multi-cylinder drying. The purpose of the steam and condensate system is to provide a sufficient amount of steam to the dryers and to handle the condensed steam. The cylinders in a drying section are divided in separate dryer groups, normally between five and ten groups. The steam pressure in the different dryer groups can then be controlled individually go obtain the desired pressure profile through the drying section, from the first group to the last one. Since the steam inside the cylinder can be regarded as saturated because of the continuous condensation at the cylinder wall, there is a direct correlation between the steam pressure and steam temperature and you could also talk about a temperature profile. For most paper grades, dryer steam pressure is increased gradually for drying capacity and run ability reasons.

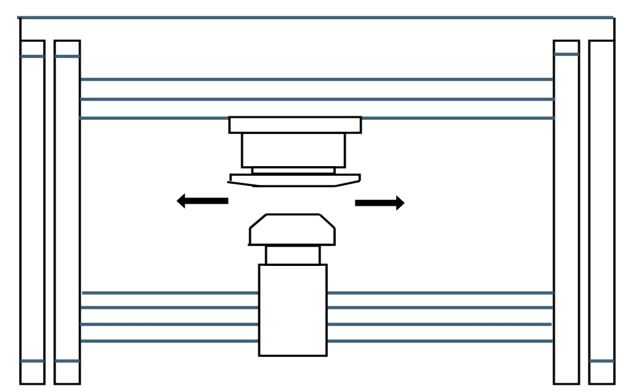

Fig. 2. Quality control scanner moves the sensor back and forth across the sheet by courtesy of ABB Ltd

\section{Materials and Methods}

\subsection{PIC controller}

It Contains flash program memory ( $8 \mathrm{~K}$ bytes), Data memory (368 bytes) EEPROM Data memory(256 bytes). There are 15 types of interrupts available in PIC 16F. It Contains five ports named it is as A, B, C, D and E. There are 3 timers named it as timer 0 ( 8 bits), time1 (16 bits) and timer 2 ( 8 bits). Serial communication is classified in to synchronous (MSSP) and asynchronous (UART) communication. Parallel communication can be had using PSP ports. It contains 10 bit ADC with 8 input channels. It contains only minimum instruction of 35 numbers. The nonlinear cruise control system was considered and it was modelled using state space representation and approximated using open loop Ziegler Nichols tuning method. Various PI and PID tuning rules were applied to verify the performance measurement like ISE, IAE and ITAE. This analysis is simulated in MATLAB and proteus environment [9]. This paper is the real time implementation analysis of nonlinear model of cruise control prototype using DC motor in simulated in proteus virtual system modelling. PIC18F Microcontroller was used to control the temperature based upon the setpoint. This system comprises of temperature sensor, PIC Microcontroller, Relay and LCD display. Initially, temperature sensor is used to measure the thermal energy values and then it is converted into electrical signal which is given as input to the Microcontroller through ADC model. Now Microcontroller compares the difference between the set point and measured value. If the difference is more than $10 \%$ then switch on the relay other wise it remains in the same state. The Microcontroller provides an on-off mechanism based on the temperature [10]. The implementation of PIC Microcontroller with graphical user interface in MATLAB is done to track the rotation angle of DC Servomotor. The movement of slider in GUI will act as an input signal to the microcontroller to change the rotation angle. A simulation on the performance of the system has been carried out using proteus software interface with the MATLAB and the control process was tested in real time application. This work was very useful to understand the interface between the MATLAB and Microcontroller [11]. The name of the microcontroller is Arduino ATMega2560 Processor.

\subsection{Identification of process parameters}

In general, plant parameters change due to ageing of the plant or changes in the load. Also, the process nonlinearities and time dependent characteristics cause a significant change in the dynamic parameters of the process, which necessitates identification of the process model at different operating conditions so that controller design can be affected. Here, the plant model is identified periodically and the changes in its dynamic characteristics are observed. This offers a great advantage over the conventional controller tuning methods, which uses the plant model at the nominal operating conditions. System identification is the process of constructing the mathematical model of dynamic systems from the observed input-output data. The process models describe a system transfer function in terms of zeros, poles, integration and delay terms. In process models, number of non-zero poles is represented by $\mathrm{Pn}$, where $\mathrm{P}$ stands for pole and $\mathrm{n}$ represents the number of 
non-zero poles. Pn is followed by $\mathrm{Z}$ for zero, I for integration, $\mathrm{D}$ for delay and $\mathrm{U}$ representing under-damped behavior. A P1D structure models the system as a second order system with delay as shown in (3). According to the set point of moisture, the actual values of moisture content are measured by ABB-DCS. The actual value depends on the steam pressure of dryer main group i.e., if there is a rise in steam pressure, the moisture content of the paper will be decreased. Thus with these real time data, the moisture process transfer function has been identified (pertaining to a Fixed Basis Weight of paper).

\subsection{PID control}

The general PID equation represents in the Eq. (1)

$$
U(t)=K p \times e(t)+K i \int e(t) d t+K d \times \frac{d e(t)}{d t}
$$

$\mathrm{K}_{\mathrm{p}}=$ proportional gain, $\mathrm{K}_{\mathrm{i}}$ = integral constant and $\mathrm{K}_{\mathrm{d}}=$ derivative constant

PID controllers are most common controllers in most of the industry [12-15]. Schematic diagram for PID control is shown in Fig. 4. In fact the $95 \%$ of control loops are used PID controllers. Normally parameters of these controllers are tuned either by the Empirical method (Zeigler-Nichols) or Analytical Method (Root Locus). These controllers are generally designed on the basis of linear control theory, even though the system is nonlinear in nature. It is a one type of feedback controller whose output, has a control variable $(\mathrm{CV})$ is generally based on the error (e) between

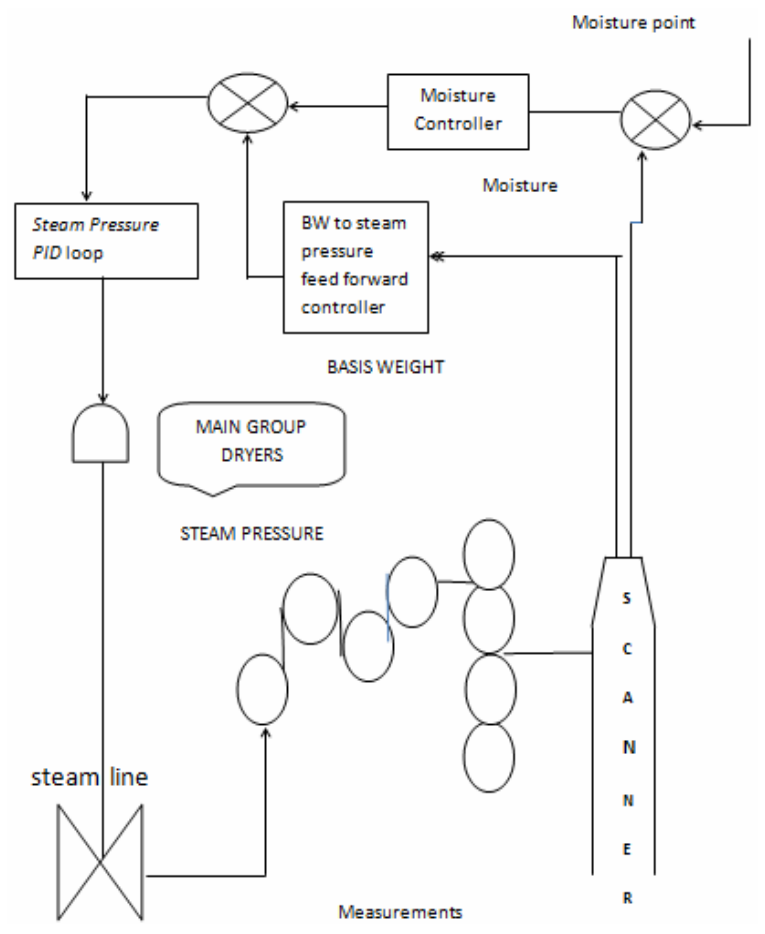

Fig. 3. MD Moisture control

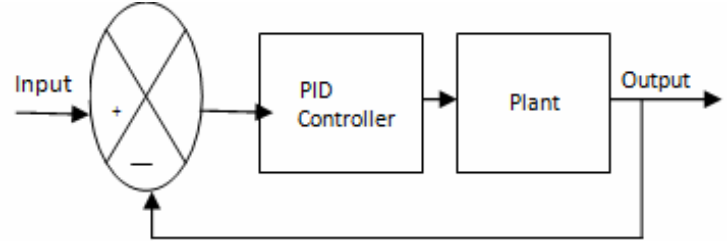

Fig. 4. Schematic of PID control

user defined set point (SP) and measured the process variable (PV). Each element of PID controller refers to a particular action taken on the error. Generally these controllers are designed by self-regulating process or by root locus technique. Hence it requires a proper tuning of the controller parameters to produce the control output according to the change in error depends on the time.

\subsection{Basic PSO}

The PSO is one of the latest algorithms inspired from the nature, was developed in 1990's by kennedy, Eberhart and shi [16-17]. PSO model consists of swarm of particles which are initialized with a population of random candidate solutions This algorithm consists of three steps.

1. Evaluate the fitness of each particle

2. Update individual and global best fitnesses and positions.

3. Update velocity and position of each particle.

The first two steps are trivial. Fitness evaluation is conducted by supplying the candidate solution to objective function. Individual and global best fitnesses positions are updated by comparing the newly evaluated fitnesses against the previous individual and global best fitnesses, are replacing the best fitnesses and positions as necessary. The velocity and position update steps are responsible for the optimization ability of the PSO algorithm. Finally, the PSO algorithm maintains the best fitness value achieved among all the particles in the swarm called the global best fitness, and the candidate solution is achieved this fitness, called global best position or global best candidate solution. The entire PSO process is represented in the flowchart Fig. 5. PSO consists of ' $n$ ' particles. Particles change its condition according to three positions.

1. To keep its inertia

2. To change the condition according to its most optimist position.

3. To change the condition according to the swarm's most optimist position.

Each particle in the swarm's position is affected by

1. most optimist position during its movement(individual experience)

2. the position of the most optimist particle in its surrounding(near experience) 


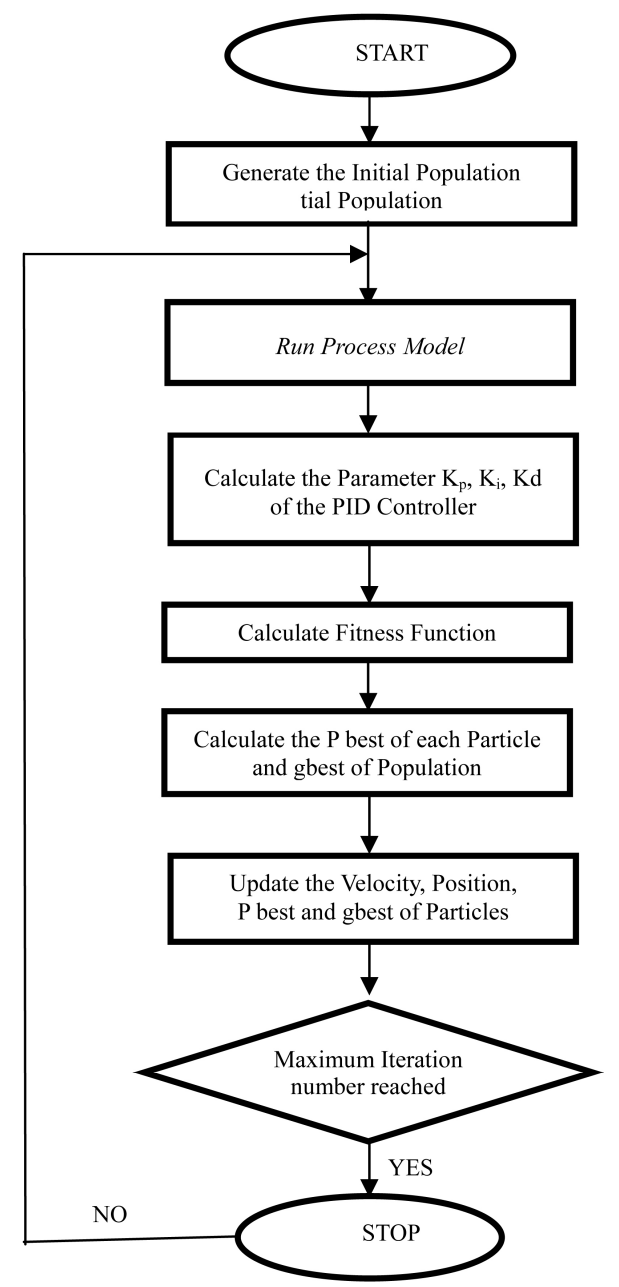

Fig. 5. Flow chart of PSO

Particles of a swarm communicate good positions to each other and adjust their own positions. Velocity is derived from the best position of all particles. Then all particles have been moved and the swarm move to close to an optimum of the fitness function.

\subsection{Basic BFOA}

Bacterial Foraging Optimization Algorithm is proposed by Passino, is a new corner to the family of nature inspired optimization algorithms-coli bacteria in multi optimal function For over the last five decades, optimization algorithms like Genetic Algorithms (GAs), Evolutionary Programming (EP), Evolutionary Strategies (ES), which draw their inspiration from evolution and natural genetics, have been dominating the realm of optimization algorithms. Recently natural swarm inspired algorithms like Particle Swarm Optimization (PSO), Ant Colony Optimization (ACO) have found their way into this domain and proved their effectiveness. Bacterial foraging optimization algorithm (BFOA) has been widely accepted as a global optimization algorithm of current interest for distributed optimization and control. BFOA is inspired by the social foraging behaviour of Escherichia coli. BFOA has already drawn the attention of researchers because of its efficiency in solving real-world optimization problems arising in several application domains. The underlying biology behind the foraging strategy of E. coli is emulated in an extraordinary manner and used as a simple optimization algorithm. Optimization is the key idea for this new algorithm. Bacteria search for the nutrients in such a manner to maximize energy obtained in per unit time. Each bacterium also communicates with others by transporting signals. Each and every bacterium takes foraging decisions after considering two prior factors. In this process, in which a bacterium moves by taking small steps while searching for nutrients, is called chemo taxis and key idea of BFOA is mimicking chemo tactic movement of virtual bacteria in the problem search space.

\subsection{Bacterial foraging optimization algorithm}

The E-coli bacterium has a control system that enables it to search for food and try to avoid noxious substances

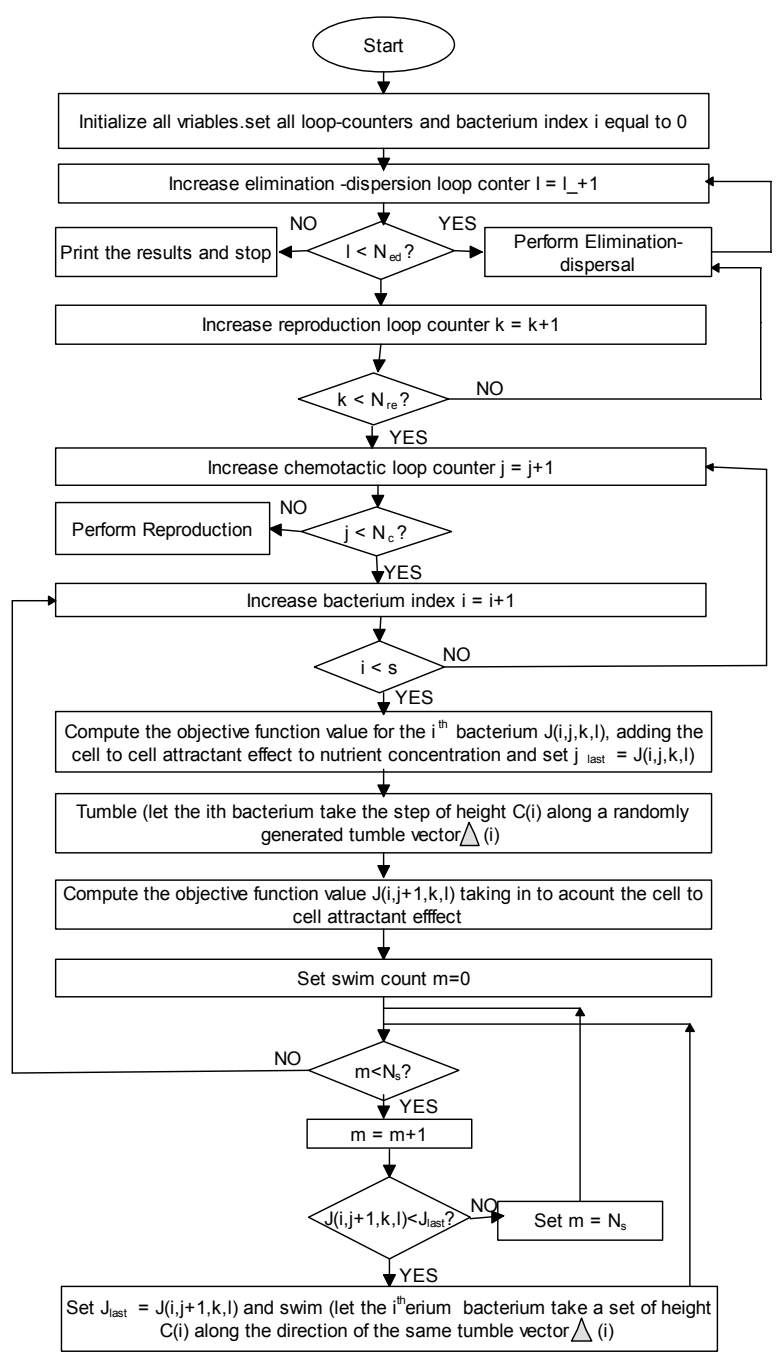

Fig. 6. Flow chart of BF. 
[18-22]. This bacteria distributed motion can modeled as four stages. The entire BFA process is represented in the flowchart Fig. 6

\subsubsection{Chemotaxis}

This process simulates the movement of an E-coli cell through swimming and tumbling via flagella. E-coli can move in two various ways. It swim for a period of time in the same direction or it may tumble and alternate between these two modes of operation for the entire lifetime.

\subsubsection{Swarming}

A group of E-coli cells arrange themselves in a travelling ring by moving up the nutrient gradient when placed amidst a semisolid matrix with a single nutrient chemoeffector. The cells when motivated by a high level of succinate, release an attractant a separate, which helps them to combined into groups and thus move as concentric patterns of swarms with high bacterial density.

\subsubsection{Reproduction}

The least healthy bacteria eventually die while each of the healthier bacteria asexually split into two bacteria, which are placed in same location. This keeps the swarm size constant.

\subsubsection{Elimination and dispersal}

Gradual or sudden changes in the local environment where a bacterium population lives may occur due to various reasons. Events can take place in such a fashion that all the bacteria in a region are killed or a group is dispersed into new location. To simulate this trend in BFOA some bacteria are liquidated at random with a very small probability while the new replacements are randomly initialized over the search space.

\subsection{BF-PSO algorithm}

The BF-PSO combines both algorithms PSO and BF. This grouping aims to make use of PSO ability to exchange social information and BF ability in finding a new solution by elimination and dispersal. The first step is to initialize parameters such as dimensions, No of bacteria in population, half the total no of bacteria, maximum no of swim length, chemotactic steps, No of reproduction steps, step size, elimination and dispersal events, PSO random parameters. The next step is generate a random direction and position. Then find the best cost function and update it after that evaluate the current position and local cost for each bacteria. Subsequently evaluate the local best position for each bacteria and global best position. Then eliminates and disperse each bacterium.

\subsection{PID tuning by BF-PSO}

The prime objective of this work is to test the performance of the developed bacterial foraging oriented by particle swarm optimization algorithm by tuning the PID controller. Attempt has been made to achieve globally minimal error squared error integral criteria in the step response of a process which is cascaded with PID controller by tuning the $K_{p}$ proportional gain, $K_{d}$ differential gain and $\mathrm{K}_{\mathrm{i}}$ integral gain values and compute the integral absolute error. In BF-PSO tuning of PID controller, best possible value of $\left[\mathrm{k}_{\mathrm{p}}, \mathrm{k}_{\mathrm{i}}\right.$ and $\left.\mathrm{k}_{\mathrm{d}}\right]$ are obtained which exhibits less overshoot, has a reasonable level of settling time, low rise time and zero steady state error. The technical specifications of paper machine and embedded processor were shown in Table 1 and Table 2.

Table 1. Technical Specifications of Paper Machine

\begin{tabular}{c|l}
\hline Components & \multicolumn{1}{c}{ Technical Specifications } \\
\hline $\begin{array}{c}\text { DCS System } \\
\text { AC 450 Controller }\end{array}$ & $\begin{array}{l}\text { AC 450 Controller } \\
\text { AI-4-20 MA, AO-4-20MA } \\
\text { AMPL - Programming }\end{array}$ \\
\hline Quality Control Scanner & $\begin{array}{l}\text { Moisture - IR Sensor } \\
\text { Output-(4-20 MA) Honey Well make }\end{array}$ \\
\hline Control Valve & $\begin{array}{l}\text { Size: 6”, Pneumatic actuated } \\
\text { Type: Air to Open }\end{array}$ \\
\hline I/P Converter & Input-4-20 MA; Output-0-6 Bar \\
\hline Dryer & $\begin{array}{l}\text { 43 Cylinders, 5 groups; } \\
\text { Material-Milled Steel }\end{array}$ \\
\hline Steam Pressure & 3. 5 Bar to 4. 5 Bar \\
\hline Steam Temperature & 150Cto180C \\
Day Production \& Machine & 350 MT \& 700M \\
\hline
\end{tabular}

Table 2. Technical specifications of embedded processor

\begin{tabular}{c|c}
\hline Microcontroller & ATMega2560 \\
\hline Operating Voltage & $5 \mathrm{~V}$ \\
\hline Input & $7-12 \mathrm{~V}$ \\
Voltage(recommended) & $6-20 \mathrm{~V}$ \\
\hline Input Voltage(limits) & 16 \\
\hline Digital I/O Pins & 54(of which 15 provide PWM output) \\
\hline Analog Input Pins & $50 \mathrm{~mA}$ \\
\hline DC Current per I/O Pin & $50 \mathrm{~mA}$ \\
\hline DC Current for 3. 3V Pin & loader \\
\hline Flash Memory & $8 \mathrm{~KB}$ \\
\hline SRAM & $4 \mathrm{~KB}$ \\
\hline EEPROM & $16 \mathrm{MHZ}$ \\
\hline Clock Speed & 256 of which $8 \mathrm{~KB}$ used boot
\end{tabular}

This paper machine setup consists of Microcontroller sensors \&Actuators. Arduino ATMega2560 processor is used as a controller of the entire setup. It gets the Input from the moisture sensor which converts the humidity level in to the electrical signal level. By analyzing there I/Ps signal, Microcontroller will ON (or) OFF the dryer section to reduce the humidity level in the paper. The program embedded into the controller controls the actuator to attain the desired response in a real time manner. The power 


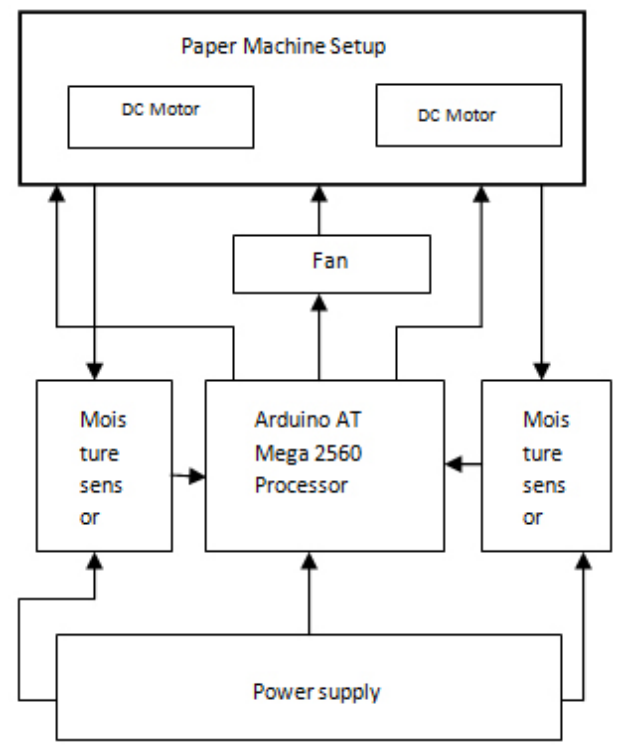

Fig. 7. Block diagram of moisture control

supply provided to the entire setup is $12 \mathrm{~V}$ DC. The available Fig. 7 is the block diagram of moisture control in paper industry.

\subsection{Memory specifications}

The ATMega2560 has $256 \mathrm{~KB}$ of flash memory for storing code( of which $8 \mathrm{~KB}$ is used for bootloader), $8 \mathrm{~KB}$ of SRAM and $4 \mathrm{~KB}$ of EEPROM (which can be read and written with the EEPROM library).

\section{Result and Discussion}

A transfer function is to validate the process is obtained with the real time data using MATLAB. The tuned values through the traditional as well as the proposed techniques are analyzed for their responses to a unit step input with the help of matlab simulation. The modeled system is represent in the Eq. (2)

$$
\mathrm{G}(\mathrm{s})=\frac{\exp (1.976) 0.978 s}{5.018 s^{2}+5.18 s+1}
$$

In this paper, a time domain criterion is used for evaluating the PID controller. A set of control parameters $\mathrm{P}, \mathrm{D}$ and I can yield a good step response that will result in performance criteria minimization in the time domain. BF-PSO based tuning method have been proved their excellence in giving better results by improving the steady state characteristics and performance indices. Furthermore, performance index is defined as a quantitative measure to depict the system performance of the designed PID controller. Using this technique an 'optimum system' can often be designed and a set of PID parameters in the system can be adjusted to meet the required condition. For the PID-controlled system, there are often only one indices to represent the system performance: IAE.

They are defined as follows in Eq. (3).

$$
\mathrm{IAE}=\int_{0}^{\infty}|e(t)| d t
$$

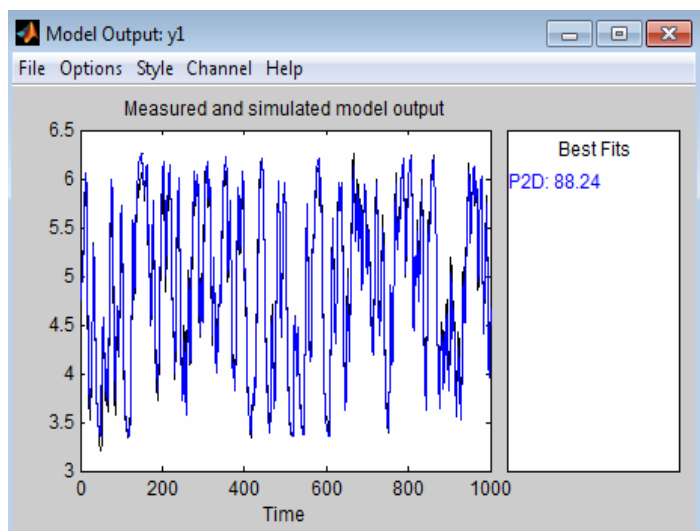

Fig. 8. Output model

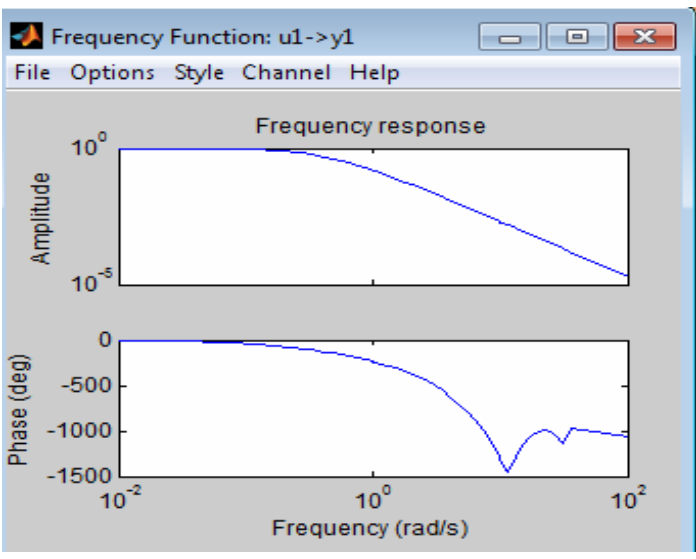

Fig. 9. Frequency function

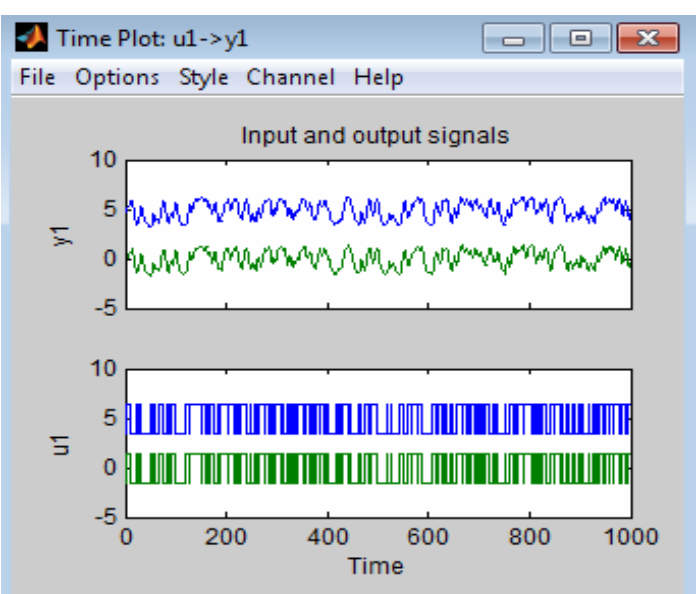

Fig. 10. Time plot 
Paper Machine Industrial Analysis on Moisture Control Using BF-PSO Algorithm and Real Time Implementation Setup through Embedded

Table 3. Comparison results

\begin{tabular}{c|c|c|c|c|c|c}
\hline \multirow{2}{*}{$\begin{array}{c}\text { Tuning } \\
\text { Method }\end{array}$} & \multicolumn{2}{|c|}{ PID Parameter } & \multicolumn{2}{|c|}{ Dynamic performance specifications } & Performane Index \\
\cline { 2 - 7 } & $\begin{array}{c}\mathrm{Kp} \\
\text { (Proportional gain) }\end{array}$ & $\begin{array}{c}\mathrm{Ki} \\
\text { (Integral gain) }\end{array}$ & $\begin{array}{c}\mathrm{Tr} \\
\text { (Rise time) }\end{array}$ & $\begin{array}{c}\mathrm{Ts} \\
\text { (Settling time) }\end{array}$ & $\begin{array}{c}\text { Mp (\%) } \\
\text { (peak overshoot) }\end{array}$ & $\begin{array}{c}\text { IAE } \\
\text { (Integral Absolute error) }\end{array}$ \\
\hline PID & 6 & 0.7 & 2.1648 & 26.8930 & 17.4868 & 2 \\
\hline BF-PSO & 1.0224 & 0.0598 & 1.7823 & 15.875 & 0 & 1.436 \\
\hline
\end{tabular}

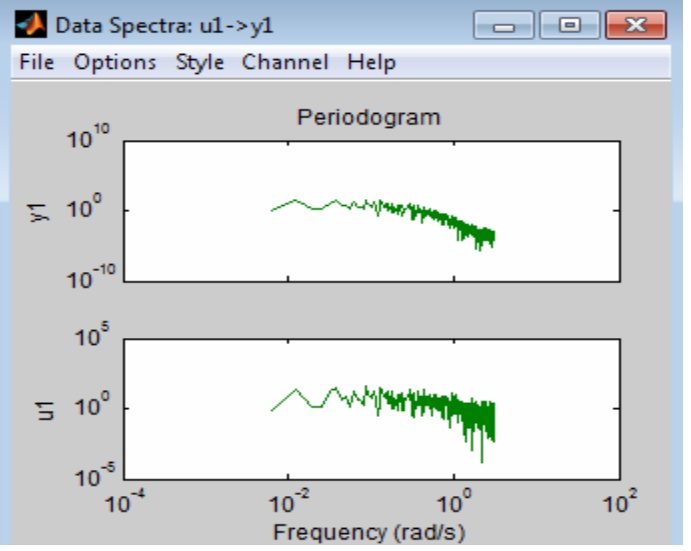

Fig. 11. Data spectrum

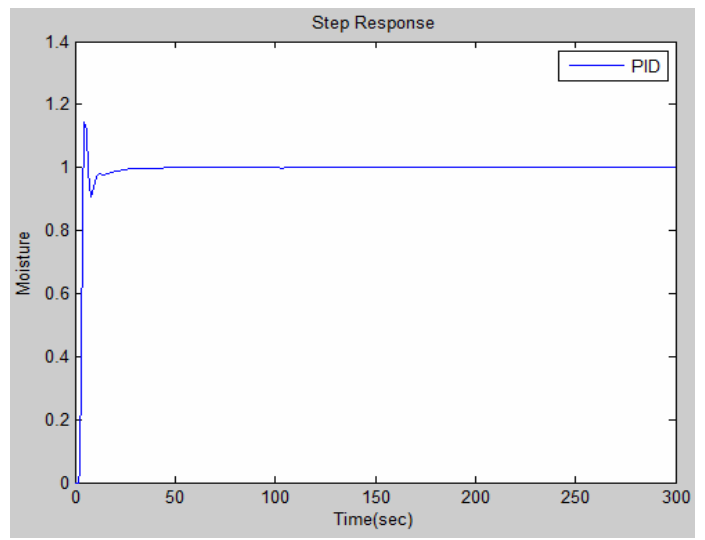

Fig. 12. Response of PID controller

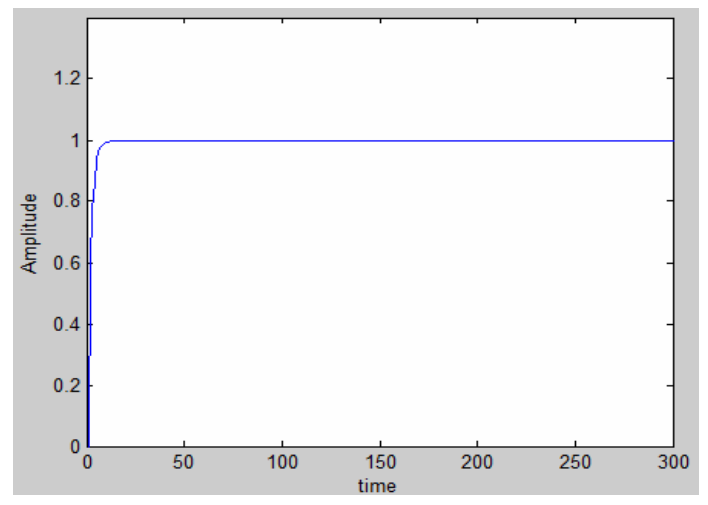

Fig. 13. Response of BF-PSO controller

Therefore, for BF-PSO based PID tuning, these performance indexes (Eqs. 2-3) will be used as the objective function. In other word, the objective in the BF-
Table 4 Pin description of moisture sensor

\begin{tabular}{c|c}
\hline Pin & Definition \\
\hline VCC & $5 \mathrm{~V}$ \\
\hline GND & GND \\
\hline DO & Digital output interface (0 and 1) \\
\hline AO & Analog output interface \\
\hline
\end{tabular}

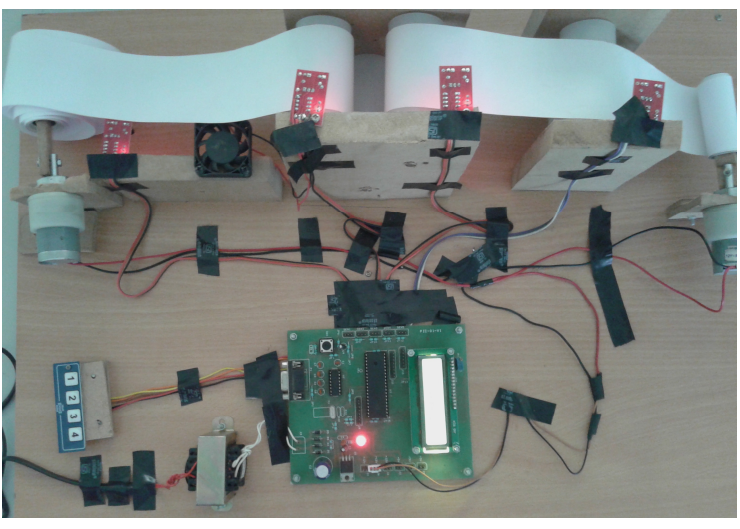

Fig. 14. Experimental set up for paper machine

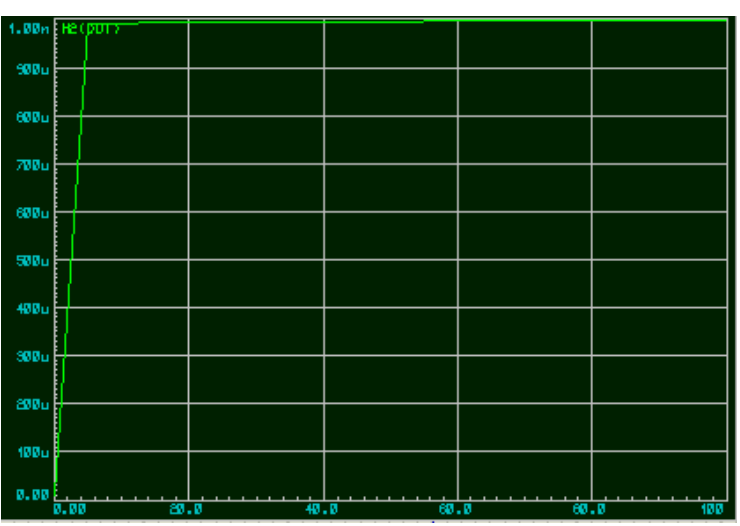

Fig. 15. Real time simulation result

PSO-based optimization is to seek a set of PID parameters such that the feedback control system has minimum performance index. Fig. 8-11 represents the Output model, Frequency function, Time plot and Data Spectrum of the system. The output response of PID and BFO-PSO are shown in the Figs. 12 and 13 respectively. The Real time prototype snapshot of the paper machine and result is shown in Figs. 14 and 15 respectively. The comparisons results are shown in Table 3 . The Pin description moisture sensor are shown in Table 4. 


\section{Conclusion}

Simulation results demonstrate the tuning method using BF-PSO which implement in this paper has provide better control performance compared with the conventional PID controller. PID controller tuning is a small-scale problem in which computational complexity is not an issue. Compared to conventionally tuned system, BF-PSO tuned system has good steady state response and performance indices From the simulations and empirical results, it is easy to conclude that the planned method performed well when compared to conventional method of tuning PID.

\section{Acknowledgements}

This work was supported by the HOD-PG Studies, Department of Electrical and Electronics Engineering, Syed Ammal Engineering College, Ramanathapuram, Tamilnsdu, India.

\section{References}

[1] M. Aníbal Valenzuela, Senior Member, IEEE, John Martin Bentley, Life Fellow, IEEE, and Robert D. Lorenz, Fellow, IEEE., Estimation of Condensate Inside Dryer Cylinders During Section Shutdown., IEEE T INDU APPLI., vol. 50, no. 3, 1668-1677, 2014.

[2] Guillermo Ramírez, Member, IEEE, Robert D. Lorenz, Fellow, IEEE, and M. Aníbal Valenzuela, Senior Member, IEEE., Observer-Based Estimation of Modulus of Elasticity for Papermaking Process, IEEE T INDU APPLI., vol. 50, no. 3, 1678-1686, 2014.

[3] Guillermo Ramírez, Member, IEEE, M. Aníbal Valenzuela, Senior Member, IEEE, andRobert D. Lorenz, Fellow, IEEE., Expert System for the Detection of Condensate Accumulation Inside Dryer Cylinders During Section Starting., IEEE T INDU APPLI., vol. 51, no. 2, 1427-1437, 2015.

[4] Ola Slätteke., Modeling and control of the paper machine drying section (Sweden by Media-Tryck, Lund University), 2006.

[5] Chang Hoe Heo., Hyunjun Cho \& Yeong -Koo Yeo, Dynamic modelling of paper drying processes, KOREAN J CHEM ENG., vol. 28, no. 8, 1651-1657, 2011.

[6] Shweta goyal., \& Rajesh Kumar., ANN Control of paper drying process, International Journal of Application or Innovation in Engineering \& Management, vol. 2, no. 7, 100-107, July2013.

[7] Paul C Austin., John Mack., Matthew McEwan., Puya Afshar., Martin Brown., \& J Maciejowski., Improved Energy Efficiency in Paper Making
Through Reducing Dryer Steam Consumption using Advanced Process Control, Papercon, 1122-1132, 2011.

[8] Karthik, C., Valarmathi, K., \& Raja Lakshmi, M., Nonlinear modelling of moisture control of drying process in paper machine, Proc Int conf on modelling optimisation and computing(ICMOC-2012), (Kumarakoil, India), 1104-1111, 2012.

[9] Prabhakar, G., Nedumal Pugazhenthi, P., \& Selvaperumal, S., Implementation Analysis of State Space Modeling and Control of Nonlinear Process using PID algorithm in MATLAB and PROTEUS Environment Applied Mechanics and Materials, vol. 573, 297-303, 2014.

[10] Sharma, S. R., Dahikar, P. B., Embedded design of temperature controller using PIC 16F876A for industries and laboratories International Journal of Innovative Research in Computer and Communication Engineering, vol. 1, no. 10, 2414-2422, 2013.

[11] Ahmed, M. A. Haidar., Chellali Benachaiba., Mohamad Zahir., Software interfacing of servo motor with Microcontroller J. Electrical Systems, vol. 1, no. 9, 84-99, 2013.

[12] Venugopal, P., Ajanta Ganguly., Priyanka Singh., Design of tuning methods of PID controller using fuzzy logic. International Journal of Emerging trends in Engineering and Development, vol. 5, no. 3, 239248, 2013.

[13] Tang, K. S., Kim Fung Man., Guanrong Chen., \& Sam Kwong., An Optimal fuzzy PID controller., IEEE T IND ELECTRON, vol. 48, no. 4, 757, 2001.

[14] Ziegler, J. G., Nichols, N. B., \& Rochester, N. Y., TRANSACTIONS OF THE A. S. M. E, 759-765, 1942.

[15] Sharifian, M. B. B., Rahnavard, R., \& Delavari, Velocity control of DC Motor based intelligent methods and optimal integral state feedback controller, International Journal of Computer Theory and Engineering, vol. 1, nol 1793-8201, 2009.

[16] Chia-Nan Ko., Chia-Ju Wu., A PSO-Tuning method for design of fuzzy PID controllers J. Vibration and Control, (2007).

[17] Zwe-Lee Gaing., A Particle swarm optimization approach for optimum design of PID Controller in AVR system, IEEE T ENERGY CONVER, vol. 19, no. 2, 384-391, 2004.

[18] Mishra, S., Bhende, C. N., Bacterial Foraging Technique-Based Optimized Active power filter for load compensation, IEEE T POWER DELIVER, vol. 22, no. 1, 457-465, 2007.

[19] Tripathy, M., Mishra, S., Bacteria Foraging-Based solution to optimize both real power loss and voltage stability., IEEE T POWER SYST, vol. 22, no. 1, 240248, 2007.

[20] Morteza Eslamian., Seyed Hossein Hosseinian., Behrooz Vahidi., Bacterial Foraging-Based solution to the unit-commitment problem., IEEE T POWER 
SYST vol. 24, no. 3, 1478-1488, 2009.

[21] Swagatam Das., Sambarta Dasgupta., Arijit Biswas, Ajith Abraham., Amit Konar., On Stability of the chemotactic dynamics in Bacterial-Foraging optimization Algorithm., IEEE T SYST MAN CY A., vol. 39, no. 3, 670-679, 2009.

[22] Mishra, S., A Hybrid least square-Fuzzy Bacterial Foraging strategy for Harmonic Estimation., IEEE T EVOLUT COMPUT., vol. 9, no. 1, 61-73, 2005. July 2001.

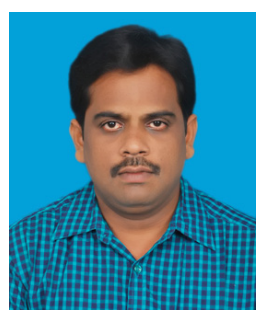

M. Senthil Kumar was born in Ramanathapuram, Tamilnadu, India 1982. He received B. E. degree in electrical and electronics engineering from Madurai kamaraj university on 2004 and M. E degree in the specialization of Control and Instrumentation from Anna University Chennai on 2006. He is currently working towards the $\mathrm{Ph}$. D. degree under the faculty of Electrical Engineering, Anna University, Chennai, Tamilnadu. He has published three research papers in refereed journals. He is currently working as an Assistant professor in Department of Electrical and Electronics Engineering, Syed Ammal Engineering College, Ramanathapuram, Tamilnadu. His areas of interest are control systems, embedded systems and instrumentation.

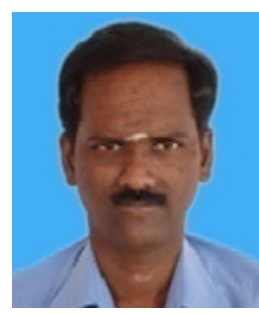

K. Mahadevan graduated in Electrical and Electronics Engineering in 1993 and Post graduated in Industrial Engineering in 1997 and PhD in 2006 from Madurai Kamaraj University, Tamilnadu, India. His fields of interest are Power System Operation and Control and Evolutionary Computation. Currently, he is Professor of Electrical \& Electronics Engineering, PSNA College of Engineering \& Technology, Dindigul, Tamilnadu, India. He has published about 20 papers in conference proceedings and 12 papers in international journals 